\title{
A study on the clinical, biochemical and hormonal profile of polycystic ovary syndrome patients attending tertiary care hospital
}

\section{Spandana J. C.*, Prasanna Kumar Shetty K.}

Department of Obstetrics and Gynecology, K. S. Hegde Medical Academy, Mangalore, Karnataka, India

Received: 01 March 2017

Accepted: 01 April 2017

*Correspondence:

Dr. Spandana J. C.,

E-mail: drspanjc@gmail.com

Copyright: () the author(s), publisher and licensee Medip Academy. This is an open-access article distributed under the terms of the Creative Commons Attribution Non-Commercial License, which permits unrestricted non-commercial use, distribution, and reproduction in any medium, provided the original work is properly cited.

\section{ABSTRACT}

Background: Polycystic ovary syndrome (PCOS) is one of the most common endocrine disorder of reproductive age affecting $5 \%$ to $10 \%$ of women worldwide. It is a heterogenous, multifactorial, complex genetic disorder. PCOS receives a considerable attention because of its high prevalence and metabolic, reproductive and cardiovascular consequences.

Methods: A cross sectional observation study of 100 PCOS patients was carried out between January 2014 to July 2015 in Gynaecology out-patient and Infertility OPD, Justice K. S. Hegde charitable hospital, Mangalore. The clinical, biochemical and hormonal profile of these patients were analysed and correlation was done between clinical features and biochemical and hormonal profile.

Results: The prevalence of PCOS was $6.3 \%$ in the Gynaecology out-patient visits and 37.14\% among infertile women. Menstrual irregularity was the most common complaint accounting for $31 \%$ followed by infertility (23\%). Elevated leutinizing hormone and elevated LH: FSH was significant in irregular menstrual group. The prevalence of metabolic syndrome in our study was $21.3 \%$. Spearmans correlation between various clinical and laboratory parameters showed menstrual cycle and body mass index(BMI) had a fair positive correlation and was significant. WHR (waist hip ratio) showed 21 times risk for metabolic syndrome.

Conclusions: The study showed that most of our polycystic ovary syndrome subjects were hirsute, with central obesity and overweight or obese. Oligomenorrhea was the most common presentation. Among the various risk factors studied, WHR (waist hip ratio) showed 21 times risk for metabolic syndrome. Obese women with PCOS had more severe ovulatory dysfunction and need more attention for their appropriate management.

Keywords: Body mass index, Hirsutism, Obese, Polycystic ovary syndrome

\section{INTRODUCTION}

Polycystic ovary syndrome (PCOS) is one of the most common endocrine disorder of reproductive age affecting $5 \%$ to $10 \%$ of women worldwide. ${ }^{1}$ It is a heterogenous, multifactorial, complex genetic disorder.

PCOS was first described by Stein and Leventhal in 1935. In May 2003 Rotterdam consensus workshop was held in Rotterdam, Netherlands on PCOS, sponsored by European Society for Human Reproduction and
Embryology (ESHRE) and the American Society for Reproductive Medicine (ASRM). ${ }^{2,3}$ For diagnosis two out of three criteria should be fulfilled, they are:

- Oligo-ovulation or anovulation;

- Clinical and/or biochemical signs of hyperandrogenism (with the exclusion of other causes of androgen excess like cushing's syndrome, congenital adrenal hyperplasia, thyroid abnormalities, androgen-secreting tumours and hyperprolactinemia);

- Polycystic ovaries(PCO) detected on ultrasound. 
The PCO definition was revised in 2003. Then Balen and co-workers suggested that 12 or more follicles in one ovary, each follicle measuring 2-9 $\mathrm{mm}$ in diameter and/or volume of the ovary $>10 \mathrm{ml} .^{4}$

PCOS is frequently associated with obesity and insulin resistance. Obesity has long been recognized as one of the features of PCOS, and 40-80\% of women with PCOS are overweight or obese.

The mechanisms by which obesity influences the pathophysiology and clinical manifestations of PCOS are not completely understood, but obesity has an important impact on the severity of hyperandrogenism, menstrual irregularities and insulin resistance. ${ }^{5}$ The report of the bearded diabetic woman by Archard and Thiers in 1921 was a landmark in recognition of association between glucose intolerance and hyperandrogenism (HA).

The original National Cholesterol Education Programme -Adult Treatment Panel III (NCEP - ATP111) criteria in 2001 defines metabolic syndrome as the co-occurrence of three or more of the following risk factors (i) central obesity with waist circumference $\geq 88 \mathrm{~cm}$ in women, (ii) elevated systolic and/or diastolic blood pressure of $\geq 130 / 85 \mathrm{mmHg}$, (iii) impaired fasting serum glucose $\geq 110 \mathrm{mg} / \mathrm{dL}$, (iv) elevated fasting serum triglycerides $\geq 150 \mathrm{mg} / \mathrm{dL}$, and (v) fasting high-density lipoprotein (HDL) cholesterol $<50 \mathrm{mg} / \mathrm{dL}{ }^{6}$

PCOS receives a considerable attention because of its high prevalence and metabolic, reproductive and cardiovascular consequences. Indians are known to have high prevalence of insulin resistance, so the prevalence of PCOS may be high in our population.

The objective of this study was to the clinical, biochemical and hormonal profile of patients with polycystic ovary syndrome (PCOS) in patient population from rural Mangalore and to correlate the various clinical presentations with the biochemical and hormonal profile in PCOS patients.

\section{METHODS}

This is a cross sectional observational type of study includes 100 patients of PCOS in the age group between 15-35 years attending gynaecology out-patient department and infertility clinic, Justice K. S. Hegde charitable hospital, Mangalore. The study was carried out between January 2014-July 2015.

\section{Inclusion criteria}

- Women presenting with oligo/amenorrhea

- Non-pregnant between 15-35 years of age giving consent

- Hyperandrogenic (clinical or biochemical)

- Diagnosed as PCOS by ultrasound

\section{Exclusion criteria}

- Pregnancy

- Symptomatic disease (liver, kidney, heart or other symptomatic diseases)

- Age $>35$ years, <15years

\section{Work-up of patients}

- PCOS patients were selected based on the Rotterdam's 2003 criteria. After fulfilling the selection criteria, all women were counselled about the study and informed written consent was obtained.

- A detailed history was obtained from cases for intake of any hormonal drugs, including OCP as well as medication for lowering blood pressure, blood lipids and glucose.

- Menstrual history in detail was taken. Secondary amenorrhea was defined as an absence of menstrual cycles more than 6 months. Oligomenorrhea was defined as a delay in menstruation for $>35$ days to 6 months. Family history was obtained regarding diabetes mellitus and hypertension in the first and second degree relatives, menstrual disorders, hirsutism and early baldness in male relatives (father and/or brothers).

- Patients were screened for clinical signs of hyperandrogenism (acne, oily skin and hirsutism).

- Clinical hyperandrogenism was defined using a modified Ferriman-Gallawey (FG) score for evaluating and quantifying hirsutism in women using nine body areas (upper lip, chin, chest, upper and lower abdomen, thighs, upper and lower back and upper arm). Hair growth was rated from 0 (no growth of terminal hair) to 4 (extensive hair growth) in each of the nine locations. A score $>/=8$ was indicative of androgen excess. Transvaginal USG was undertaken to detect PCO's.

- Height in cm (bare foot, standing erect against wall), weight in $\mathrm{kg}$ (in a weighing scale, bare foot, light clothing), waist circumference in $\mathrm{cm}$ (minimum circumference at the waist level), hip circumference in $\mathrm{cm}$ (maximum circumference below the level of umbilicus) was measured by principal investigator.

- Patient was allowed to drink $75 \mathrm{gm}$ glucose solution and blood was drawn after two hours i.e. 75 grams glucose tolerance test(GTT), <140 was considered normal, 140-199 as impaired sugars, >/= 200 as diabetic.

- Additionally, blood pressure is measured in patients in sitting position, $>/=140 / 85$ was considered as hypertension.

- Obesity was assessed according to WHO criteria as a body mass index (BMI). Calculated as BMI=weight $/$ height $^{2}$, kilogram per meter ${ }^{2}$. Classified as <18.5 Underweight, 18.5-24.9 Normal, 25-29.9 Overweight, 30-34.9 Obese, >=35 morbid obese.

- Body fat distribution was assessed by measurements of the waist to hip girth ratio (WHR). A WHR $<0.85$ was considered normal. 
- Hormone assay is done in the early follicular phase samples were taken on day 2 of menstruation for all women in the fasting state. FSH, LH, prolactin, DHEAS, total testosterone, Fasting blood sugar(FBS), Fasting lipid profile (FLP) were done. The normal cutoff for FSH and LH was taken as $<12.5 \mathrm{mIU} / \mathrm{ml}$. A prolactin level $<25 \mathrm{ng} / \mathrm{ml}$ was taken as normal, a total testosterone of $<70 \mathrm{ng} / \mathrm{dl}$ was taken as normal. LH: FSH ratio $>2: 1$ was taken significant. TSH was done irrespective of menstrual cycle, a TSH >4.5 was considered as hypothyroid.

- Fasting lipid profile (FLP) was done in PCOS patients to diagnose dyslipidemia and metabolic syndrome, normal values taken were $\mathrm{TC}<200$, HDL $>50$, LDL $<130$, TG $<150$ an VLDL $<50$.

- Clinical features, associated diseases, family history, hormone levels and ultrasonography results are all analyzed.

\section{Data management and statistical methods}

- Statistical analyses were performed using the statistical package for the social statistics (SPSS) 16 software package.

- Continous variables were summerized as mean +/standard deviation and analysed using sample t-test. Categorical variables were expressed as proportions and analysed by chi-square test.

- Univariate logistic regression analysis was applied to quantify the association between clinical and laboratory variables and the presence of metabolic syndrome.

- A p value less than 0.05 was considered statistically significant.

\section{RESULTS}

A total of 4891 patients visited Gynaecology Out Patient between January 2014 to July 2015 and 49 patients were found to have newly detected PCOS. The prevalence of PCOS was $6.3 \%$ in the general gynaecological out-patient visits. Similarly, in the patients attending the Infertility Outpatient Department during the study period, there were 51 new cases and 287 old cases, making the prevalence in the infertile population $37.14 \%$ among 910 total visits. Table 1 shows the demographic profile of PCOS patients. The mean age group of the patients was $27.32 \pm 5$ SD. The mean BMI was 25.95+/-4.96. Table 2 shows the marital and parity status of patients in our study. The mean age of menarche was $12.62 \pm 1.11$ years. The mean duration of infertility was 7.02 \pm 3.29 . Table 3 shows clinical profile of 100 PCOS patients. About $97 \%$ were detected to have PCOS in ultrasonography. FLP was done by 80 patients out of 100 patients due to financial problem. Table 4 shows the Biochemical and hormonal profile of PCOS patients. Metabolic syndrome diagnosis was made according to NCEP ATP 3 criteria. The prevalence of metabolic syndrome was calculated and it is found to be $21.3 \%$.
Table 1: Demographic and morbidity profile of the study population.

\begin{tabular}{|ll|}
\hline Age in years & n $(\%)$ \\
\hline $15-20$ & $13(13)$ \\
\hline $21-25$ & $19(19)$ \\
\hline $26-30$ & $43(43)$ \\
\hline $31-35$ & $25(25)$ \\
\hline Religion & \\
\hline Christian & $13(13)$ \\
\hline Hindu & $71(71)$ \\
\hline Muslim & $16(16)$ \\
\hline Education & \\
\hline Degree & $20(20)$ \\
\hline High school & $36(36)$ \\
\hline Middle school & $24(24)$ \\
\hline PUC & $20(20)$ \\
\hline Socio economic status & \\
\hline Lower & $15(15)$ \\
\hline Middle & $65(65)$ \\
\hline Upper & $20(20)$ \\
\hline Body mass index & $6(6)$ \\
\hline$<18.5$ (underweight) & $40(40)$ \\
\hline $18.5-24.9$ (normal) & $33(33)$ \\
\hline $25-29.9$ (overweight) & $17(17)$ \\
\hline $30-34.9$ (obese) & $04(04)$ \\
\hline$>=35$ (morbid obese) & \\
\hline
\end{tabular}

Table 2: Marital and infertility status of PCOS patients.

\begin{tabular}{|c|c|}
\hline Characteristics & n $(\%)$ \\
\hline \multicolumn{2}{|l|}{ Marital history } \\
\hline Married & $74(74)$ \\
\hline Unmarried & $26(26)$ \\
\hline \multicolumn{2}{|l|}{ Fertility status } \\
\hline Parous & $23(31.1)$ \\
\hline Nulliparous & $51(68.9)$ \\
\hline \multicolumn{2}{|l|}{ Type of infertility } \\
\hline Primary infertility & $42(82)$ \\
\hline Secondary infertility & $09(18)$ \\
\hline \multicolumn{2}{|l|}{ Duration of infertility } \\
\hline $1-5$ years & 20(39) \\
\hline 6-10years & $23(45)$ \\
\hline 11-15years & $18(16)$ \\
\hline
\end{tabular}

Among the various variables compared there was a significant association between PCOS patients with acanthosis and BMI $(\mathrm{P}<0.05)$. There was a significant association between testosterone levels of PCOS patients and BMI. Comparing infertility and menstrual cycles shows that there is significant association between both the groups. The clinical and biochemical characteristics were compared between PCOS patients with regular and irregular cycles, the statistically significant factors in irregular group were age, weight, BMI, WC, WHR, LH, LH/FSH. 
Table 3: Clinical profile of 100 PCOS patients.

\begin{tabular}{|l|l|}
\hline Signs of hyperandrogenism & n $(\%)$ \\
\hline Hirsutism & $71(71)$ \\
\hline Acne & $20(20)$ \\
\hline Acanthosis nigricans & $17(17)$ \\
\hline Androgenic alopecia & $07(07)$ \\
\hline Waist circumference (WC) & \\
\hline$<=88$ & $56(56)$ \\
\hline$>88 \mathrm{~cm}$ & $44(44)$ \\
\hline Waist hip ratio $(\mathbf{W H R})$ & \\
\hline$<0.8$ & $62(62)$ \\
\hline$>=0.8$ & $38(38)$ \\
\hline Manifestations of ovarian dysfunction & \\
\hline Oligomenorrhea & $59(59)$ \\
\hline Secondary Amenorrhea & $04(04)$ \\
\hline Ultrasound polycystic ovaries & $93(93)$ \\
\hline Associated conditions & \\
\hline Blood pressure & $89(89)$ \\
\hline$<130 / 85$ mm of Hg & $11(11)$ \\
\hline$>=130 / 85$ mm of Hg & $10(12.5)$ \\
\hline Dyslipidemia & $13(16.3)$ \\
\hline Total cholesterol $>/=200 \mathrm{mg} / \mathrm{dl}$ & $14(17.5)$ \\
\hline HDL $<50$ mg/dl & $17(21.3)$ \\
\hline TG $>150$ mg/dl & $11(11)$ \\
\hline Metabolic syndrome & $20(20)$ \\
\hline Diabetes mellitus & \\
\hline Impaired blood sugars & \\
\hline
\end{tabular}

Table 4 shows Spearmans correlation between the different clinical features and laboratory parameter, Menstrual cycles and BMI have a fair positive correlation indicating that menstrual cycles irregulaties increase with increase in the BMI and this is significant with $\mathrm{p}$ value of 0.004 .

Table 4: Biochemical and hormonal profile of PCOS patients.

\begin{tabular}{|c|c|c|c|}
\hline Investigations & Values & n $(\%)$ & Mean \pm SD \\
\hline \multirow{3}{*}{$\mathrm{TSH}$} & $<0.27$ & $2(2)$ & \multirow{3}{*}{$3.53 \pm 3.28$} \\
\hline & $0.27-4.2$ & $76(76)$ & \\
\hline & $>4.2$ & $22(22)$ & \\
\hline LH & $>12$ & $27(27)$ & $8.68 \pm 5.55$ \\
\hline \multirow{2}{*}{ Prolactin } & $<25 \mathrm{ng} / \mathrm{ml}$ & $87(87)$ & \multirow{2}{*}{$14.76 \pm 14.07$} \\
\hline & $>25 \mathrm{ng} / \mathrm{ml}$ & $13(13)$ & \\
\hline \multirow{2}{*}{ LH/FSH } & $<2: 1$ & $65(65)$ & \multirow{2}{*}{$1.68 \pm 1.04$} \\
\hline & $>2: 1$ & $35(35)$ & \\
\hline \multicolumn{3}{|l|}{ Testosterone } & \multirow{3}{*}{$0.89 \pm 0.69$} \\
\hline & $<0.8$ & $56(56)$ & \\
\hline & $>/=0.8$ & $44(44)$ & \\
\hline
\end{tabular}

Table 5 shows Univariate logistic regression analysis to find out the predictor for the metabolic syndrome, it showed WHR is the variable which has 21 times risk for metabolic syndrome. Menstrual cycles and BMI have a fair positive correlation indicating that menstrual cycles irregulates increase with increase in the BMI and this is significant with $\mathrm{p}$ value of 0.004 .

Table 5: Spearmans correlation between the different clinical features and laboratory parameter.

\begin{tabular}{|c|c|c|c|c|c|c|}
\hline \multicolumn{7}{|l|}{ Correlations } \\
\hline & & & BMI & LH/FSH & Menstrual cycles & Hirsutism \\
\hline \multirow{12}{*}{ Spearman's rho } & \multirow{3}{*}{ BMI } & Correlation Coefficient & 1.000 & & & \\
\hline & & $P$ value & - & & & \\
\hline & & $\mathrm{N}$ & 100 & & & \\
\hline & \multirow{3}{*}{ LH/FSH } & Correlation Coefficient & -0.128 & 1.000 & & \\
\hline & & $P$ value & 0.204 & - & & \\
\hline & & $\mathrm{N}$ & 100 & 100 & & \\
\hline & \multirow{3}{*}{ Menstrual cycles } & Correlation Coefficient & $0.289^{* *}$ & $0.242^{*}$ & 1.000 & \\
\hline & & $P$ value & 0.004 & 0.015 & - & \\
\hline & & $\mathrm{N}$ & 100 & 100 & 100 & \\
\hline & \multirow{3}{*}{ Hirsutism } & Correlation Coefficient & $0.514^{* *}$ & $0.201^{*}$ & $0.364^{* *}$ & 1.000 \\
\hline & & $P$ value & $<0.001$ & 0.045 & $<0.001$ & - \\
\hline & & $\mathrm{N}$ & 100 & 100 & 100 & 100 \\
\hline
\end{tabular}

**Correlation is significant at the 0.01 level (2-tailed). *Correlation is significant at the 0.05 level (2-tailed).

Table 6: Univariate logistic regression analysis predicting the metabolic syndrome.

\begin{tabular}{|lllll|} 
& P value & Odds ratio & 95\% C.I. for odds ratio & Upper \\
\hline Age & 0.070 & 1.155 & 0.988 & 1.350 \\
\hline Acanthosis & 0.396 & 2.153 & 0.367 & 12.640 \\
\hline Weight & 0.618 & 0.966 & 0.843 & 1.107 \\
\hline BMI & 0.069 & 1.417 & 0.973 & 2.063 \\
\hline WHR & 0.424 & 21.362 & 0.012 & 38614.192 \\
\hline Family h/o dm/htn & 0.373 & 2.047 & 0.423 & 9.915 \\
\hline Constant & 0.000 & 0.000 & & \\
\hline
\end{tabular}


Table 6 shows that WHR is the variable which has 21 times risk for metabolic syndrome.

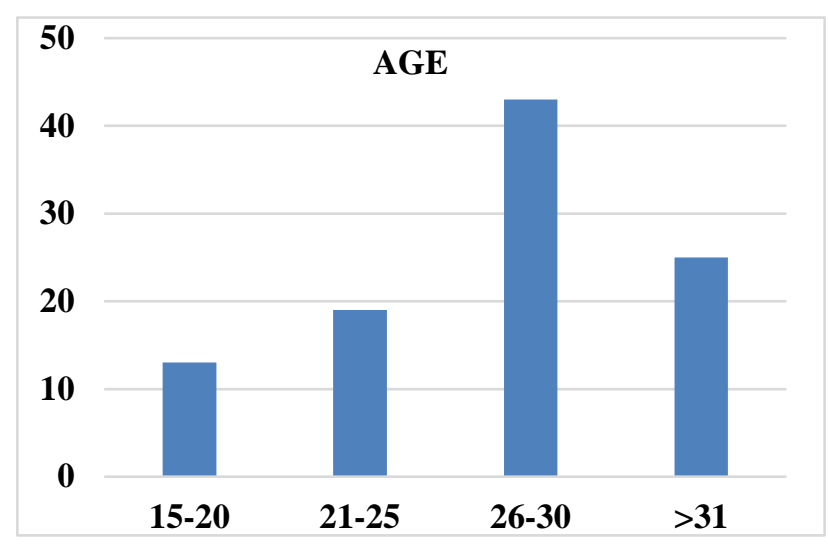

Figure 1: Age distribution of PCOS.

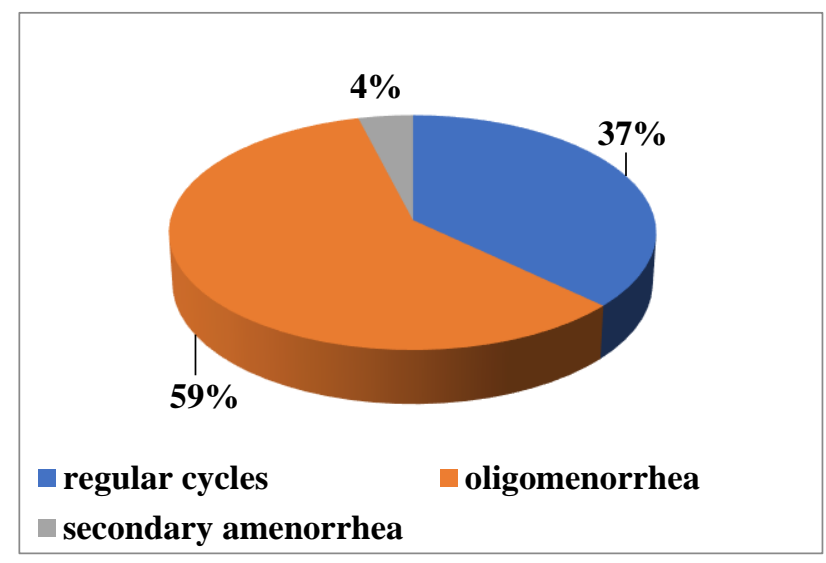

Figure 2: Menstrual pattern distribution.

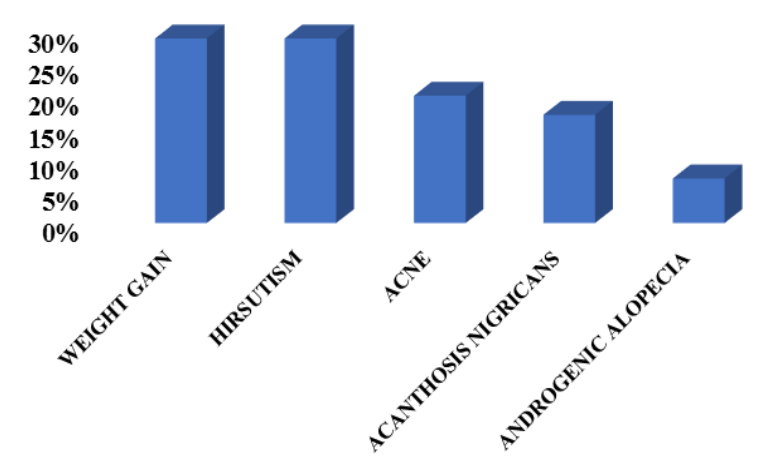

Figure 3: Clinical features distribution.

\section{DISCUSSION}

PCOS is a common endocrine disorder encountered by the clinician in women of reproductive age affecting 5$10 \%$ of the general population. ${ }^{7}$ This study was therefore undertaken to study the broad range of clinical, biochemical and hormonal features associated with this syndrome.
The prevalence of PCOS using Rotterdam criteria in our study was $6.3 \%$ among gynecological out-patient visits. Nidhi R et al in 2011 found that prevalence of PCOS among adolescents to be $9.13 \%$ in Andhra Pradesh, South India. ${ }^{8}$ The prevalence of PCOS among infertile women was $37.14 \%$, accounting to one third of the patients. Couzin estimated that $40 \%$ of infertile women have PCOS. ${ }^{9}$ This is comparable to our study.

PCOS is reported to be more prevalent in younger ages $(<35)$ than among older women, proposing that due to a physiological decline of the follicular cohort leading to a normalized ovarian ultrasonographic appearance with advancing age. In our study mean age of the patients was $27+/-5.0$ and majority of the patients belonged to the age group between 26-30 years (43\%). In a study done by Muralidhara et al in KMC Mangalore in 2012 mean age among PCOS patients was $27+/-7.1$ which is comparable to our study..$^{10}$

In our study among 100 PCOS patients, 74\% were married and $26 \%$ were unmarried. Among married women, about $31.1 \%$ were parous and $68.9 \%$ were nulliparous. Among nulliparous patients, $82 \%$ presented with primary infertility and $18 \%$ with secondary infertility. In a study done in Tanzania, A. B. Pembe showed that among 102 women, $12.5 \%$ were single, $87.5 \%$ were married, among married $62.5 \%$ were nulliparous and $37.5 \%$ were parous. ${ }^{11}$ The prevalence of infertility was $39.4 \%$ of which $46.7 \%$ had primary and $53.1 \%$ had secondary infertility which is comparable to our study.

In our study $59 \%$ had oligomenorrhea, $37 \%$ had regular cycles and $4 \%$ had secondary amenorrhea. In a study done by Sunitha J Ramanand et al at Kohlapur, Maharashtra found that Oligomenorrheoa was present in $65 \%$ patients. $^{12}$ In our study though more number of overweight and obese patients had oligomenorrhea, the difference between obese and non-obese was not significant. About $37.1 \%$ of infertility patients had oligomenorrhea which was significant in hirsute women $(\mathrm{p}<0.001)$.

Androgenic features like acne was present in $20 \%$ of the patients, acanthosis nigricans in $17 \%$ of the patients and androgenic alopecia was present in $7 \%$. Waist circumference was $>88 \mathrm{~cm}$ in $44 \%$ of the patients and WHR $>0.85$ was seen in $38 \%$ of the patients highlighting that Indians have more central obesity even at low BMI. Blood pressure recording showed $11 \%$ had $\mathrm{BP}>=130 / 85$ $\mathrm{mm}$ of hg. In a study done by Kavitha Mandrelle et al in CMC, Vellore in 2011 among 120 PCOS patients, hirsutism was present in $28.3 \%$, acne in $9.2 \%$, acanthosis was seen in $15.8 \%$, WHR was more in $45.8 \%$ of the patients and $11.7 \%$ had $\mathrm{BP}>/=130 / 85 \mathrm{~mm}$ of hg which is comparable to our study. ${ }^{13}$

Abnormality of the hypothalamic-pituitaryovarian or adrenal axis has been implicated in PCOS. Disturbance in 
the pulsatility of gonadotrophin releasing hormone $(\mathrm{GnRH})$ results in the relative increase in $\mathrm{LH}$ to $\mathrm{FSH}$ release. An abnormal feedback mechanism by ovarian estrogen is blamed to play role in this discriminated increase in LH release. Many researchers consider elevated LH: FSH $(>2)$ diagnostic for PCOS. In this study, day 2 hormonals profile the results showed that, $6 \%$ had increased FSH, 27\% had elevated LH and LH: FSH $(>2)$ was elevated in $35 \%$ of patients and prolactin was high in $13 \%$ of the patients. Elevated LH and elevated LH: FSH was significant in irregular menstrual group. Elevated total testosterone was elevated in $44 \%$ of the patients. Nizem FI et al in Benghazi-Libiya showed that $16 \%$ had elevated LH/FSH ratio, $31 \%$ had hyperprolactinemia, $26.4 \%$ had elevated testosterone. ${ }^{14}$

Every patient was evaluated for altered sugars and lipid abnormalities our study showed, $22 \%$ had hypothyroidism and was significant in the PCOS group with BMI $>25$. About $11 \%$ had impaired sugars, $20 \%$ were diagnosed to have diabetes. FBS and 2 hours 75 grams GTT was significant in the PCOS group with metabolic syndrome, with irregular cycles, patients with BMI $>25$. In a study conducted by Muralidhara et al in 86 PCOS patients, they found that $33 \%$ had FBS $>100 \mathrm{mg} \%$, PPBS were high in about $25 \%$ and impaired glucose tolerance was reported by $17 \% .^{10}$

In obese women, excess insulin and androgens may contribute to the development of the PCOS and metabolic syndrome. The android pattern of fat distribution may be the result as well as the cause of hyperandrogenism, setting up a vicious circle of hyperinsulinism, hyperandrogenism, central adiposity and metabolic abnormalities. The prevalence of metabolic syndrome was $21.3 \%$. The age distribution of metabolic syndrome showed maximum number of patients about $52.9 \%$ were in the age group 31-35years. Among the various risk factors studied, WHR showed 21 times risk for metabolic syndrome. In a study done by Soo Jin Chae et al in Seoul, South Korea in 2008 showed that all PCOS subgroups were more associated with metabolic syndrome than the control group ( $\mathrm{p}<0.05) .{ }^{15}$ All of the parameters that made up the metabolic syndrome, except fasting glucose were significantly more prevalent in PCOS women than in controls ( $\mathrm{p}<0.05)$, no differences in clinical or biochemical parameters were noted in PCOS group.

\section{Limitations}

- Fasting insulin levels are not done in our study, so insulin resistance among could not be studied.

- It is a cross sectional observational study, so long term complications of PCOS could not be studied.

\section{CONCLUSION}

The study showed that most of our polycystic ovary syndrome subjects were hirsute, with central obesity and overweight or obese. Oligomenorrhea was the most common presentation. Among the various risk factors studied, WHR (waist hip ratio) showed 21 times risk for metabolic syndrome. Obese women with PCOS had more severe ovulatory dysfunction and need more attention for their appropriate management.

\section{AKNOWLEDGEMENTS}

Authors would like to thanks Dean and ethical committee for permitting to conduct the study and also teaching faculty of obstetrics and Gynecology department of K. S. Hegde Medical Academy, statisticians and participants of the study for their whole-hearted participation.

\section{Funding: No funding sources Conflict of interest: None declared \\ Ethical approval: The study was approved by the Institutional Ethics Committee}

\section{REFERENCES}

1. Azziz R, Woods KS, Reyna R, Key TJ, Knochenhauer ES, Yildiz BO. The prevalence and features of the polycystic ovary syndrome in an unselected population. J Clini Endocrinol Metab. 2004;89(6):2745-9.

2. Practice committee of American Society of Reproductive Medicine. The evaluation and treatment of androgen excess. Fertil Steril. 2006;86: 173-80.

3. The Rotterdam ESHRE/ASRM-Sponsored PCOS Consensus Workshop Group. Revised 2003 consensus on diagnostic criteria and long-term health risks related to polycystic ovary syndrome. Fertil Steril. 2004;81:19-25.

4. Radon PA, McMahon MJ, Meyer WR. Impaired glucose tolerance in pregnant women with polycystic ovary syndrome. Obstet Gynecol. 1999;94:194-7.

5. Pasquali R, Gambineri A, Pagotto U. The impact of obesity on reproduction in women with polycystic ovary syndrome. BJOG. 2006;113:1148-59.

6. Lepor NE, Vogel RE. National Cholesterol Education Program Adult Treatment Panel III. Summary of the third report of the National Cholesterol Education Program Adult Treatment Panel III. Rev Cardiovas Med. 2001;2:160-5.

7. Escobar-Morreale H, Carmina E, Dewailly D, Gambineri A, Kelestimur F, Moghetti P, et al. Epidemiology, diagnosis and management of hirsutism: a consensus statement by the Androgen Excess and Polycystic Ovary Syndrome Society. Hum Reprod Update. 2012;19(2):207.

8. Ramanand SJ, Ramanand JB, Raparti GT, Ghanghas RR, Halasawadekar NR, Patil PT, et al. High sensitivity C-reactive protein (hs-CRP) and clinical characteristics, endocrine, metabolic profile in Indian women with PCOS: a correlation. Int J Reprod Contracept Obstet Gynecol. 2014;3(1):118-26.

9. Hussein B, and Alalaf S. Prevalence and characteristics of polycystic ovarian syndrome in a 
sample of infertile Kurdish women attending IVF infertility center in maternity teaching hospital of Erbil City.Open J Obstet Gynecol. 2013;10(3):57785.

10. Muralidhara KD, Adhikari PM, Muralidhara DV. Indian Journal of Basic and Applied Medical Research. 2015;4(3):227-36.

11. Ogueh O, Zini M, Williams S, Ighere J. The Prevalence of Polycystic Ovary Morphology Among Women Attending a New Teaching Hospital in Southern Nigeria. Afr J Reprod Health. 2014; 18(1):161.

12. Ramanand SJ, Ramanand JB, Ghongane BB, Patwardhan MH, Patwardhan VM, Ghanghas R, et al. Correlation between serum adiponectin and clinical characteristics, biochemical parameters in Indian women 2 with polycystic ovary syndrome. Indian J Endocr Metab. 2014;18:221-5.

13. Mandrelle K, Kamath MS, Bondu DJ, Chandy A, Aleyamma T, George K. Prevalence of metabolic syndrome in women with polycystic ovary syndrome attending an infertility clinic in a tertiary care hospital in south India. J Hum Reprod Sci. 2012;5(1):26-31.

14. Najem F, Elmehdawi R, Swalem A. Clinical and Biochemical Characteristics of Polycystic Ovary Syndrome in Benghazi- Libya; A Retrospective study. Libyan J Med. 2008;3(2):71-4.

15. Gill H, Chae SJ, Kim JJ, Choi YM, Hwang KR, Jee $\mathrm{BC}$, et al. Clinical and biochemical characteristics of polycystic ovary syndrome in Korean women. Hum Reprod. 2008;23(8):1924-31.

Cite this article as: Spandana JC, Shetty PKK. A study on the clinical, biochemical and hormonal profile of polycystic ovary syndrome patients attending tertiary care hospital. Int J Reprod Contracept Obstet Gynecol 2017;6:1986-92. 